\title{
ASYMPTOTIC EXPANSIONS FOR THE MOMENTS OF THE BOUNDARY FUNCTIONALS OF THE RENEWAL REWARD PROCESS WITH A DISCRETE INTERFERENCE OF CHANCE
}

\author{
Rovshan Aliyev ${ }^{1,2}$, Nurgul Okur Bekar ${ }^{3}$, Tahir Khaniyev ${ }^{4}{ }^{2 *}$, Ihsan Unver $^{3}$ \\ ${ }^{1}$ Department of Statistics and Computer Sciences, Karadeniz Technical University, \\ 61080, Trabzon, Turkey, aliyevrovshan@yahoo.com \\ 2 Institute of Cybernetics of Azerbaijan National Academy of Sciences, \\ F. Agayev str.9, AZ 1141, Baku, Azerbaijan \\ ${ }^{3}$ Department of Mathematics, Karadeniz Technical University, 61080, Trabzon, Turkey, \\ ihsanunver@ktu.edu.tr,ngrokur@gmail.com \\ ${ }^{4}$ Department of Industrial Engineering, TOBB University of Economics and \\ Technology, Sogutozu, 06560, Ankara, Turkey, tahirkhaniyev@etu.edu.tr
}

\begin{abstract}
In this study, two boundary functionals $\mathrm{N}_{1}$ and $\tau_{1}$ of the renewal reward process with a discrete interference of chance $(\mathrm{X}(\mathrm{t}))$ are investigated. A relation between the moment generating function $\left(\Psi_{N}(z)\right)$ of the boundary functional $N_{1}$ and the Laplace transform $\left(\Phi_{\tau}(\mu)\right)$ of the boundary functional $\tau_{1}$ is obtained. Using this relation, the exact formulas for the first four moments of the boundary functional $\tau_{1}$ are expressed by means of the first four moments of the boundary functional $\mathrm{N}_{1}$. Moreover, the asymptotic expansions for the first four moments of these boundary functionals are established when the random variables $\left\{\zeta_{n}\right\}, n \geq 0$, which describe a discrete interference of chance, have an exponential distribution with parameter $\lambda>0$. Finally, the accuracy of the approximation formulas for the moments $\left(\mathrm{EN}_{1}^{\mathrm{k}}\right)$ of the boundary functional $\mathrm{N}_{1}$ are tested by Monte Carlo simulation method.
\end{abstract}

Keywords- Renewal Reward Process, Discrete Interference of Chance, Boundary Functional, Laplace Transform, Asymptotic Expansion, Monte Carlo Method.

\section{INTRODUCTION}

A number of very interesting problems of queuing, reliability, risk, sequential analysis and stock control theory, mathematical insurance, statistics and physics are expressed by means of the renewal reward process with a discrete interference of chance. Numerous studies have been done about a renewal reward process with a discrete interference of chance because of their practical and theoretical importance (see, for instance, [1]-[9]).

Brown and Solomon [2] obtained the second-order asymptotic expansions for the first and second moments of the renewal reward process. Jewell [4] generalized the study of the fluctuations of a reward renewal process.

As known, it is very important to investigate the boundary functionals of the stochastic processes. There are many studies on this topic in the literature. In [7] was 
obtained the third-order asymptotic expansions for the moments of the generalized renewal process. Moreover, a number of authors have investigated a harmonic renewal measure. We mention here contributions by Alsmeyer [1]. It is not difficult to see that there exist some connection between harmonic renewal measures and first passage times. Khaniyev [5] investigated the probability characteristics of a boundary functional of a semi-continuous random process with reflecting and delaying screens.

In [9] was investigated the distribution function and additive functional of the renewal reward process with a discrete interference of chance $(\mathrm{X}(\mathrm{t}))$. In this study, unlike the study [9], we will investigate two important boundary functional of the process $X(t)$, when the random variables $\left\{\zeta_{n}\right\}, n \geq 0$, which describe a discrete interference of chance, have an exponential distribution.

Let's consider the following inventory model before expressing the problem mathematically.

The model. Assume that the stock level in a depot at the initial time $(t=0)$ is equal to $\mathrm{X}(0) \equiv \mathrm{X}_{0} \equiv \mathrm{s}+\zeta_{0}$, where $0<\mathrm{s}<\infty$ represents the stock control level. In addition, it is assumed that at random times $T_{1}, T_{2}, \ldots, T_{n}, \ldots$ the stock level $(X(t))$ in the depot decreases by $\eta_{1}, \eta_{2}, \ldots, \eta_{n}, \ldots$, respectively, until the stock level $X(t)$ falls below the predetermined control levels. Thus the stock level in the depot changes as follows:

$$
X\left(T_{1}\right) \equiv X_{1}=s+\zeta_{0}-\eta_{1}, X\left(T_{2}\right) \equiv X_{2}=s+\zeta_{0}-\left(\eta_{1}+\eta_{2}\right), \ldots, X\left(T_{n}\right) \equiv X_{n}=s+\zeta_{0}-\sum_{i=1}^{n} \eta_{i},
$$

where, $\eta_{n}$ represents the quantity of the $n^{\text {th }}$ demand, $n=1,2,3, \ldots$.

In other words, demands are inserted to the system at the random times $\mathrm{T}_{\mathrm{n}}=\sum_{\mathrm{i}=1}^{\mathrm{n}} \xi_{\mathrm{i}}$, where $\xi_{\mathrm{n}}$ represents the time between $(\mathrm{n}-1)^{\text {th }}$ and $\mathrm{n}^{\text {th }}$ demands, $\mathrm{n}=1,2,3, \ldots$. The system passes from one state to another by jumping at time $\mathrm{T}_{\mathrm{n}}$, according to the quantities of demand $\left\{\eta_{n}\right\}, n \geq 1$. This variation of the system continues up to a certain random time $\tau_{1}$, where $\tau_{1}$ is the first time that the stock level $\mathrm{X}(\mathrm{t})$ drops below the control level $\mathrm{s}>0$. When this occurs, the system is immediately brought to the state $s+\zeta_{1}$, where $\zeta_{1} \in[0, \infty)$. Thus the first period completes and the second one starts. Afterwards, the process $X(t)$ continues to change from the new initial state $\mathrm{s}+\zeta_{1}$, similar to the way it changed in the first period. When the stock level $\mathrm{X}(\mathrm{t})$ drops below $\mathrm{s}$, for the second time, the stock level is brought to the random level $\mathrm{s}+\zeta_{2}$, similar to the preceding period. Afterwards, starting from its initial state $\mathrm{s}+\zeta_{2}$, the process $X(t)$ will continue to change in a similar way, as mentioned above.

Our aim is to examine the characteristics of both the time periods $\left(\tau_{n}\right)$ and the number of jumps $\left(\mathrm{N}_{\mathrm{n}}\right)$ occurring in these time periods. It will be enough to examine the characteristics of the random variables $N_{1}$ and $\tau_{1}$ at first period since the random variables $\zeta_{\mathrm{n}}$ expressing the discrete interference of chance have the same distribution. 
In this study, we assumed the random variables $\zeta_{n}, n=0,1,2, \ldots$ have an exponential distribution because we do not want the amount of order in depot to be excessive. Large volume stocks are held in depots for long times until they are sold. Prolonged stocking leads to an increase in holding costs. Therefore it is unwanted to have such large volume orders. In other words, it is desired that the probability of large volume orders be low. To express such a model, we found appropriate to use exponential distribution in which the probability of small volume orders is high and vice versa. On the other hand, if we assume that the random variables $\zeta_{n}$ have exponential distribution, the approach of Laplace transformation is possible to apply in calculations. Besides, simplifying many calculations, this leads us to obtain many important formulas that have practical significance.

Let's now construct the process $\mathrm{X}(\mathrm{t})$ mathematically.

\section{MATHEMATICAL CONSTRUCTION OF THE PROCESS X(t)}

Let $\left\{\xi_{n}\right\}$ and $\left\{\eta_{n}\right\}, n=1,2,3, \ldots$ are two independent sequences of random variables defined on any probability space $(\Omega, \mathfrak{I}, \mathrm{P})$, such that variables in each sequence independent and identically distributed. Introduce also, sequence of identically distributed random variables $\left\{\zeta_{n}\right\}, n=0,1,2, \ldots$ which describes the discrete interference of chance. Suppose that $\xi_{i}$ 's, $\eta_{i}$ 's and $\zeta_{i}$ 's take on positive values and these distribution functions be denoted by $\Phi(\mathrm{t}), \mathrm{F}(\mathrm{x})$ and respectively. So,

$$
\Phi(\mathrm{t})=\mathrm{P}\left\{\xi_{1} \leq \mathrm{t}\right\}, \mathrm{t}>0 ; \mathrm{F}(\mathrm{x})=\mathrm{P}\left\{\eta_{1} \leq \mathrm{x}\right\}, \mathrm{x}>0, \pi(\mathrm{z})=\mathrm{P}\left\{\zeta_{1} \leq \mathrm{z}\right\}, \mathrm{z}>0 .
$$

Using the initial sequences of the random variables $\left\{\xi_{n}\right\}$ and $\left\{\eta_{n}\right\}$, define the renewal sequences $\left\{\mathrm{T}_{\mathrm{n}}\right\}$ and $\left\{\mathrm{S}_{\mathrm{n}}\right\}$ as follows:

$$
\mathrm{T}_{\mathrm{n}}=\sum_{\mathrm{i}=1}^{\mathrm{n}} \xi_{\mathrm{i}}, \mathrm{S}_{\mathrm{n}}=\sum_{\mathrm{i}=1}^{\mathrm{n}} \eta_{\mathrm{i}}, \mathrm{n} \geq 1, \mathrm{~T}_{0}=\mathrm{S}_{0}=0,
$$

and a sequence of integer valued random variables $\mathrm{N}_{\mathrm{n}}$ as:

$$
\mathrm{N}_{0}=0 ; \quad \mathrm{N}_{\mathrm{n}+1}=\inf \left\{\mathrm{k} \geq \mathrm{N}_{\mathrm{n}}+1: \zeta_{\mathrm{n}}-\mathrm{S}_{\mathrm{k}}+\mathrm{S}_{\mathrm{N}_{\mathrm{n}}}<0\right\}, \mathrm{n} \geq 0,
$$

where $\inf \{\varnothing\}=+\infty$ is stipulated.

Moreover, put

$$
v(\mathrm{t})=\max \left\{\mathrm{n} \geq 0: \mathrm{T}_{\mathrm{n}} \leq \mathrm{t}\right\}, \mathrm{t}>0 ; \tau_{0}=0 ; \tau_{\mathrm{n}}=\mathrm{T}_{\mathrm{N}_{\mathrm{n}}}=\sum_{\mathrm{i}=1}^{\mathrm{N}_{\mathrm{n}}} \xi_{\mathrm{i}} ; \mathrm{n} \geq 1 .
$$

We can now construct desired stochastic process $\mathrm{X}(\mathrm{t})$ as follows:

$$
X(t)=s+\zeta_{n}-S_{v(t)}+S_{N_{n}} \text {, for each } t \in\left[\tau_{n}, \tau_{n+1}\right), n \geq 0 ;
$$

where $S_{v\left(\tau_{n}+0\right)}=S_{N_{n}}$ and $s$ is any real positive number.

The process $\mathrm{X}(\mathrm{t})$ is called as a renewal reward process with a discrete interference of chance. One of the main aims of this study is to obtain a relation between 
characteristics the boundary functionals $\tau_{1}$ and $N_{1}$ of the process $X(t)$. Moreover, the other purpose of this present study is to express the exact formulas for the first four moments of $\tau_{1}$ by means of $\mathrm{N}_{1}$ and obtain the third-order asymptotic expansions for the first four moments of these boundary functionals.

\section{THE EXACT RESULTS FOR THE CHARACTERISTICS OF THE BOUNDARY FUNCTIONALS}

In this section, we will express the exact formulas for the first four moments of the boundary functional $\tau_{1}$ by means of the first four moments of $\mathrm{N}_{1}$.

Let's define the following transforms of the variables $\xi_{1}, N_{1}$ and $\tau_{1}$ :

$$
\begin{aligned}
& \varphi_{\xi}(\mu)=\mathrm{E}\left(\exp \left(-\mu \xi_{1}\right)\right), \varphi_{\mathrm{N}(\mathrm{x})}(\mathrm{k})=\mathrm{E}\left(\exp \left(-\mathrm{kN}_{1}(\mathrm{x})\right)\right), \\
& \Psi_{\mathrm{N}(\mathrm{x})}(\mathrm{z})=\mathrm{E}\left[\mathrm{z}^{\mathrm{N}_{1}(\mathrm{x})}\right], \Phi_{\tau(\mathrm{x})}(\mu)=\mathrm{E}\left(\exp \left(-\mu \tau_{1}(\mathrm{x})\right)\right) .
\end{aligned}
$$

Here $\mu \geq 0 ; \mathrm{k} \equiv \mathrm{k}_{\mu}=\ln \left(1 / \varphi_{\xi}(\mu)\right) \geq 0 ; \mathrm{x} \geq 0 ;|\mathrm{z}| \leq 1 ; \exp (\mathrm{A})=\mathrm{e}^{\mathrm{A}}$.

The relation between these four transforms is given by means of the following proposition.

Proposition 3.1. The transform $\Phi_{\tau(\mathrm{x})}(\mu)$ of the boundary functional $\tau_{1}(\mathrm{x})$ can be expressed by means of the transforms $\varphi_{\xi}(\mu)$ and $\Psi_{\mathrm{N}(\mathrm{x})}(\mathrm{z})$ as follows:

$\Phi_{\tau(\mathrm{x})}(\mu)=\Psi_{\mathrm{N}(\mathrm{x})}\left(\varphi_{\xi}(\mu)\right)=\varphi_{\mathrm{N}(\mathrm{x})}\left(\mathrm{k}_{\mu}\right), \mu \geq 0, \mathrm{k}_{\mu} \geq 0$.

Proof. By definition of the boundary functional $\tau_{1}(\mathrm{x})$, we can write:

$$
\Phi_{\tau(\mathrm{x})}(\mu)=\mathrm{E}\left(\exp \left(-\mu \tau_{1}(\mathrm{x})\right)\right)=\mathrm{E}\left(\exp \left(-\mu \sum_{\mathrm{i}=1}^{\mathrm{N}_{1}(\mathrm{x})} \xi_{\mathrm{i}}\right)\right) \text {. }
$$

On the other hand, it is possible to write the following expression, because the sequences of the random variables $\left\{\xi_{i}\right\}$ and $\left\{\eta_{i}\right\}, i \geq 1$ are independent:

$$
\begin{aligned}
\Phi_{\tau(\mathrm{x})}(\mu) & =\sum_{\mathrm{n}=1}^{\infty} \mathrm{E}\left(\exp \left(-\mu \sum_{\mathrm{i}=1}^{\mathrm{n}} \xi_{\mathrm{i}}\right)\right) \mathrm{P}\left\{\mathrm{N}_{1}(\mathrm{x})=\mathrm{n}\right\} \\
& =\sum_{\mathrm{n}=1}^{\infty}\left[\varphi_{\xi}(\mu)\right]^{\mathrm{n}} \mathrm{P}\left\{\mathrm{N}_{1}(\mathrm{x})=\mathrm{n}\right\}=\Psi_{\mathrm{N}(\mathrm{x})}\left(\varphi_{\xi}(\mu)\right) .
\end{aligned}
$$

Moreover, since $\varphi_{\xi}(\mu) \rightarrow 1$, as $\mu \rightarrow 0$, then $\mathrm{k}_{\mu}=\ln \left(1 / \varphi_{\xi}(\mu)\right) \rightarrow 0$.

Therefore, $\Psi_{\mathrm{N}(\mathrm{x})}\left(\varphi_{\xi}(\mu)\right)$ can be written:

$$
\begin{aligned}
\Psi_{\mathrm{N}(\mathrm{x})}\left(\varphi_{\xi}(\mu)\right) & =\mathrm{E}\left[\varphi_{\xi}(\mu)^{\mathrm{N}_{1}(\mathrm{x})}\right]=\mathrm{E}\left[\exp \left(\mathrm{N}_{1}(\mathrm{x}) \ln \left(\varphi_{\xi}(\mu)\right)\right)\right] \\
& =\mathrm{E}\left[\exp \left(-\mathrm{k}_{\mu} \mathrm{N}_{1}(\mathrm{x})\right)\right]=\varphi_{\mathrm{N}(\mathrm{x})}\left(\mathrm{k}_{\mu}\right) .
\end{aligned}
$$

In this case the desired connection can be written as follows:

$$
\Phi_{\tau(\mathrm{x})}(\mu)=\Psi_{\mathrm{N}(\mathrm{x})}\left(\varphi_{\xi}(\mu)\right)=\varphi_{\mathrm{N}(\mathrm{x})}\left(\mathrm{k}_{\mu}\right), \mathrm{k}_{\mu} \geq 0, \mu \geq 0 .
$$

This completes the proof of the Proposition 3.1.

As the result of the Proposition 3.1, it is easily to obtain the following theorem.

Theorem 3.1. Let the initial sequences of the random variables $\left\{\xi_{n}\right\},\left\{\eta_{n}\right\}$ and $\left\{\zeta_{n}\right\}$ be satisfied the following supplementary conditions: 
i) $\alpha_{4}=\mathrm{E}\left(\xi_{1}^{4}\right)<\infty$; ii) $\mathrm{m}_{4}=\mathrm{E}\left(\eta_{1}^{4}\right)<\infty$; iii) the random variables $\left\{\zeta_{\mathrm{n}}\right\}, \mathrm{n} \geq 0$ which describe the discrete interference of chance have an exponential distribution with parameter $\lambda>0$. Then the first four moments of the boundary functional $\tau_{1}(\mathrm{x})$ can be expressed by the same moments of the boundary functional $\mathrm{N}_{1}(\mathrm{x})$, as follows:

1) $\mathrm{E} \tau_{1}(\mathrm{x})=\alpha_{1} \mathrm{EN}_{1}(\mathrm{x})$,

2) $\mathrm{E} \tau_{1}^{2}(\mathrm{x})=\alpha_{1}^{2} \mathrm{EN}_{1}^{2}(\mathrm{x})+\left(\alpha_{2}-\alpha_{1}^{2}\right) \mathrm{EN}_{1}(\mathrm{x})$,

3) $\mathrm{E}_{1}^{3}(\mathrm{x})=\alpha_{1}^{3} \mathrm{EN}_{1}^{3}(\mathrm{x})+3 \alpha_{1}\left(\alpha_{2}-\alpha_{1}^{2}\right) \mathrm{EN}_{1}^{2}(\mathrm{x})+\left(2 \alpha_{1}^{3}-3 \alpha_{1}^{2} \alpha_{2}+\alpha_{3}\right) \mathrm{EN}_{1}(\mathrm{x})$,

4) $\mathrm{E}_{1}^{4}(\mathrm{x})=\alpha_{1}^{4} \mathrm{EN}_{1}^{4}(\mathrm{x})+6 \alpha_{1}^{2}\left(\alpha_{2}-\alpha_{1}^{2}\right) \mathrm{EN}_{1}^{3}(\mathrm{x})+\left(11 \alpha_{1}^{4}-18 \alpha_{1}^{2} \alpha_{2}+4 \alpha_{1} \alpha_{3}+3 \alpha_{2}^{2}\right) \mathrm{EN}_{1}^{2}(\mathrm{x})$

$$
+\left(\alpha_{4}+12 \alpha_{1}^{2} \alpha_{2}-4 \alpha_{1} \alpha_{3}-3 \alpha_{2}^{2}-6 \alpha_{1}^{4}\right) \mathrm{EN}_{1}(\mathrm{x})
$$

where $\alpha_{\mathrm{k}}=\mathrm{E}\left(\xi_{1}^{\mathrm{k}}\right)<\infty, \mathrm{k}=\overline{1,4}$.

Proof. Denote the Laplace transforms of $\Phi_{\tau(\mathrm{x})}(\mu)$ and $\varphi_{\mathrm{N}(\mathrm{x})}\left(\mathrm{k}_{\mu}\right)$ by the $\tilde{\Phi}_{\tau}(\lambda, \mu)$ and $\tilde{\varphi}_{\mathrm{N}}\left(\lambda, \mathrm{k}_{\mu}\right)$. Since $\Phi_{\tau(\mathrm{x})}(\mu)=\varphi_{\mathrm{N}(\mathrm{x})}\left(\mathrm{k}_{\mu}\right)$, then

$$
\tilde{\Phi}_{\tau}(\lambda, \mu)=\int_{0}^{\infty} \mathrm{e}^{-\lambda \mathrm{x}} \Phi_{\tau(\mathrm{x})}(\mu) \mathrm{dx}=\int_{0}^{\infty} \mathrm{e}^{-\lambda \mathrm{x}} \varphi_{\mathrm{N}(\mathrm{x})}\left(\mathrm{k}_{\mu}\right) \mathrm{dx}=\tilde{\varphi}_{\mathrm{N}}\left(\lambda, \mathrm{k}_{\mu}\right) .
$$

Taking a derivative from both sides of (3.5) respect to parameter $\mu$, as $\mu \rightarrow 0$, we get:

$$
\begin{aligned}
& \left.\frac{\partial \tilde{\Phi}_{\tau}(\lambda, \mu)}{\partial \mu}\right|_{\mu \rightarrow 0}=-\left.\int_{0}^{\infty} \mathrm{e}^{-\lambda \mathrm{x}} \mathrm{E}\left[\tau_{1}(\mathrm{x}) \mathrm{e}^{-\mu \tau_{1}(\mathrm{x})}\right] \mathrm{dx}\right|_{\mu \rightarrow 0}=-\int_{0}^{\infty} \mathrm{e}^{-\lambda \mathrm{x}} \mathrm{E}\left(\tau_{1}(\mathrm{x})\right) \mathrm{dx}, \\
& \left.\frac{\partial \tilde{\varphi}_{\mathrm{N}}\left(\lambda, \mathrm{k}_{\mu}\right)}{\partial \mu}\right|_{\mu \rightarrow 0}=-\left.\int_{0}^{\infty} \mathrm{e}^{-\lambda \mathrm{x}} \mathrm{E}\left[\mathrm{k}_{\mu}^{\prime} \mathrm{N}_{1}(\mathrm{x}) \mathrm{e}^{-\mathrm{k}_{\mu} \mathrm{N}_{1}(\mathrm{x})}\right] \mathrm{dx}\right|_{\mu \rightarrow 0}=-\lim _{\mu \rightarrow 0} \int_{0}^{\infty} \mathrm{e}^{-\lambda \mathrm{x}} \mathrm{k}_{\mu}^{\prime} \mathrm{EN}_{1}(\mathrm{x}) \mathrm{dx} .
\end{aligned}
$$

Note that, $\lim _{\mu \rightarrow 0} \mathrm{k}_{\mu}^{\prime}=\alpha_{1}=\mathrm{E}\left(\xi_{1}\right)$. From the formulas (3.6)-(3.7), we can obtain:

$$
\mathrm{E} \tau_{1}(\mathrm{x})=\alpha_{1} \mathrm{EN}_{1}(\mathrm{x}) \text { (Wald's identity) }
$$

Using the similar method, the formulas (3.2)-(3.4) can be analogously obtained.

This completes the proof of the Theorem 3.1.

Denote $\tilde{\mathrm{EN}} \mathrm{N}_{1}^{\mathrm{k}}(\lambda)=\int_{0}^{\infty} \mathrm{E}\left(\mathrm{N}_{1}^{\mathrm{k}}(\mathrm{x})\right) \mathrm{d} \pi(\mathrm{x}), \mathrm{k}=\overline{1,4}$. Here $\pi(\mathrm{x})$ is the distribution function of the exponential distribution with parameter $\lambda>0$.

Theorem 3.2. Let the conditions of the Theorem 3.1 be satisfied. Then the exact expressions for the first four moments of $\mathrm{N}_{1}(\mathrm{x})$ can be written, as follows:
1) $\tilde{\mathrm{EN}} \mathrm{N}_{1}(\lambda)=\frac{1}{1-\varphi_{\eta}(\lambda)}$
2) $\tilde{\mathrm{E}} \mathrm{N}_{1}^{2}(\lambda)=\frac{2}{\left(1-\varphi_{\eta}(\lambda)\right)^{3}}-\frac{1}{\left(1-\varphi_{\eta}(\lambda)\right)^{2}}$,
3) $\tilde{\mathrm{EN}}_{1}^{3}(\lambda)=\frac{6}{\left(1-\varphi_{\eta}(\lambda)\right)^{3}}-\frac{6}{\left(1-\varphi_{\eta}(\lambda)\right)^{2}}+\frac{1}{1-\varphi_{\eta}(\lambda)}$, 
4) $\tilde{\mathrm{EN}_{1}^{4}}(\lambda)=\frac{24}{\left(1-\varphi_{\eta}(\lambda)\right)^{4}}-\frac{36}{\left(1-\varphi_{\eta}(\lambda)\right)^{3}}+\frac{14}{\left(1-\varphi_{\eta}(\lambda)\right)^{2}}-\frac{1}{1-\varphi_{\eta}(\lambda)}$,

where $\varphi_{\eta}(\lambda)=E\left(\exp \left(-\lambda \eta_{1}\right)\right)$.

Proof. By definition of the boundary functional $\mathrm{N}_{1}(\mathrm{x})$, we can write:

$\mathrm{P}\left\{\mathrm{N}_{1}(\mathrm{x}) \geq \mathrm{n}\right\}=\mathrm{P}\left\{\mathrm{S}_{\mathrm{n}} \leq \mathrm{x}\right\}, \mathrm{n} \geq 1$.

Note that,

$$
\mathrm{P}\left\{\mathrm{S}_{\mathrm{n}} \leq \mathrm{x}\right\}=\mathrm{F}_{\mathrm{n}}(\mathrm{x})=\mathrm{F}^{*_{\mathrm{n}}}(\mathrm{x}), \mathrm{n} \geq 1, \mathrm{~F}_{0}(\mathrm{x})=\mathrm{F}^{* 0}(\mathrm{x})=\varepsilon(\mathrm{x})=\left\{\begin{array}{ll}
1, & \mathrm{x} \geq 0 \\
0, & \mathrm{x}<0
\end{array}\right. \text {. }
$$

On the other hand, it is not difficult to see the following result, because the sequence of the random variables $\left\{\eta_{i}\right\}, i \geq 1$ are independent:

$$
\mathrm{EN}_{1}(\mathrm{x})=\sum_{\mathrm{n}=1}^{\infty} \mathrm{nP}\left\{\mathrm{N}_{1}(\mathrm{x})=\mathrm{n}\right\}=\sum_{\mathrm{n}=1}^{\infty} \mathrm{n}\left[\mathrm{F}_{\mathrm{n}-1}(\mathrm{x})-\mathrm{F}_{\mathrm{n}}(\mathrm{x})\right]=\sum_{\mathrm{n}=0}^{\infty} \mathrm{F}_{\mathrm{n}}(\mathrm{x}) \equiv \mathrm{U}_{\mathrm{\eta}}(\mathrm{x}) .
$$

Due to the conditions of the Theorem 3.1, because the sequence of random variables $\left\{\zeta_{n}\right\}$ has an exponential distribution with parameter $\lambda>0$, we get:

$$
\tilde{\operatorname{EN}}{ }_{1}(\lambda)=\int_{0}^{\infty} \operatorname{EN}_{1}(x) \mathrm{d} \pi(x)=\int_{0}^{\infty} \operatorname{EN}_{1}(x) \lambda \mathrm{e}^{-\lambda \mathrm{x}} \mathrm{dx}=\lambda \tilde{\mathrm{U}}_{\eta}(\lambda)=\frac{1}{1-\varphi_{\eta}(\lambda)}, \lambda>0 .
$$

Using the similar method, the formulas (3.9)-(3.11) can be analogously obtained.

This completes proof of the Theorem 3.2.

\section{THE APPROXIMATION FORMULAS FOR THE FIRST FOUR MOMENTS OF $\mathrm{N}_{1}$ AND $\tau_{1}$}

In this section the asymptotic methods of investigation for the moments of the boundary functionals $\mathrm{N}_{1}(\mathrm{x})$ and $\tau_{1}(\mathrm{x})$ are considered, as $\mathrm{x} \rightarrow \infty$.

Theorem 4.1. Let the conditions of the Theorem 3.1 be satisfied. Then the thirdorder asymptotic expansions for the first four moments of the boundary functional $\mathrm{N}_{1}(\mathrm{x})$ can be written as follows, when $\mathrm{x} \rightarrow \infty$ :

1) $\mathrm{EN}_{1}(\mathrm{x})=\frac{\mathrm{x}}{\mathrm{m}_{1}}+\frac{\mathrm{m}_{2}}{2 \mathrm{~m}_{1}^{2}}+\mathrm{o}\left(\frac{1}{\mathrm{x}}\right)$,

2) $\mathrm{EN}_{1}^{2}(\mathrm{x})=\frac{\mathrm{x}^{2}}{\mathrm{~m}_{1}^{2}}+\left(\frac{2 \mathrm{~m}_{2}}{\mathrm{~m}_{1}^{3}}-\frac{1}{\mathrm{~m}_{1}}\right) \mathrm{x}+\left(\frac{3 \mathrm{~m}_{2}^{2}}{2 \mathrm{~m}_{1}^{4}}-\frac{2 \mathrm{~m}_{3}}{\mathrm{~m}_{1}^{3}}-\frac{\mathrm{m}_{2}}{2 \mathrm{~m}_{1}^{2}}\right)+\mathrm{o}(1)$,

3) $\mathrm{EN}_{1}^{3}(\mathrm{x})=\frac{\mathrm{x}^{3}}{\mathrm{~m}_{1}^{3}}+\left(\frac{9 \mathrm{~m}_{2}}{2 \mathrm{~m}_{1}^{4}}-\frac{3}{\mathrm{~m}_{1}^{2}}\right) \mathrm{x}^{2}+\left(\frac{9 \mathrm{~m}_{2}^{2}}{\mathrm{~m}_{1}^{5}}-\frac{3 \mathrm{~m}_{3}}{\mathrm{~m}_{1}^{4}}-\frac{6 \mathrm{~m}_{2}}{\mathrm{~m}_{1}^{3}}+\frac{1}{\mathrm{~m}_{1}}\right) \mathrm{x}+\mathrm{o}(\mathrm{x})$,

4) $\mathrm{EN}_{1}^{4}(\mathrm{x})=\frac{\mathrm{x}^{4}}{\mathrm{~m}_{1}^{4}}+\left(\frac{8 \mathrm{~m}_{2}}{\mathrm{~m}_{1}^{5}}-\frac{6}{\mathrm{~m}_{1}^{3}}\right) \mathrm{x}^{3}+\left(\frac{30 \mathrm{~m}_{2}^{2}}{\mathrm{~m}_{1}^{6}}-\frac{8 \mathrm{~m}_{3}}{\mathrm{~m}_{1}^{5}}-\frac{27 \mathrm{~m}_{2}}{\mathrm{~m}_{1}^{4}}+\frac{7}{\mathrm{~m}_{1}^{2}}\right) \mathrm{x}^{2}+\mathrm{o}\left(\mathrm{x}^{2}\right)$,

5) $\operatorname{Var}(\mathrm{N}(\mathrm{x}))=\left(\frac{\mathrm{m}_{2}}{\mathrm{~m}_{1}^{3}}-\frac{1}{\mathrm{~m}_{1}}\right) \mathrm{x}+\left(\frac{5 \mathrm{~m}_{2}^{2}}{4 \mathrm{~m}_{1}^{4}}-\frac{2 \mathrm{~m}_{3}}{3 \mathrm{~m}_{1}^{3}}-\frac{\mathrm{m}_{2}}{2 \mathrm{~m}_{1}^{2}}\right)+\mathrm{o}(1)$, 
where $m_{n}=E\left(\eta_{1}^{n}\right), \quad n=1,2,3$.

Proof. By the condition of the Theorem 4.1, $E\left(\eta_{1}^{3}\right)<\infty$. In this case, the following asymptotic expansion for the renewal function $\mathrm{EN}_{1}(\mathrm{x})$ is true [3], as $\mathrm{x} \rightarrow \infty$ :

$$
\mathrm{EN}_{1}(\mathrm{x})=\frac{\mathrm{x}}{\mathrm{m}_{1}}+\frac{\mathrm{m}_{2}}{2 \mathrm{~m}_{1}^{2}}+\mathrm{o}\left(\frac{1}{\mathrm{x}}\right)
$$

In this case, we will calculate the third-order asymptotic expansions for the other moments of $\mathrm{N}_{1}(\mathrm{x})$. For this aim, we can use the Theorem 3.2. By definition of $\mathrm{EN}_{1}^{2}(\mathrm{x})$ :

$$
\operatorname{EN}_{1}^{2}(x)=\sum_{n=1}^{\infty} n^{2}\left[F_{n-1}(x)-F_{n}(x)\right]
$$

Firstly, let's introduce the following notations:

$$
\mathrm{R}_{2}(\mathrm{x})=\mathrm{EN}_{1}^{2}(\mathrm{x})-\frac{\mathrm{x}^{2}}{\mathrm{~m}_{1}^{2}}-\left(\frac{2 \mathrm{~m}_{2}}{\mathrm{~m}_{1}^{3}}-\frac{1}{\mathrm{~m}_{1}}\right) \mathrm{x}, \mathrm{x}>0 ; \varphi_{\eta}(\lambda)=\mathrm{E}\left(\exp \left(-\lambda \eta_{1}\right)\right), \lambda>0 .
$$

Let $\tilde{R}_{2}(\lambda)$ denote the Laplace transform of $\mathrm{R}_{2}(\mathrm{x})$. With these notations, from the formula (4.5), we have the following relation:

$$
\tilde{\mathrm{R}}_{2}(\lambda)=\frac{1-\varphi_{\eta}(\lambda)}{\lambda} \sum_{\mathrm{n}=1}^{\infty} \mathrm{n}^{2}\left(\varphi_{\eta}(\lambda)\right)^{\mathrm{n}-1}-\frac{2}{\lambda^{3} \mathrm{~m}_{1}^{2}}-\left(\frac{2 \mathrm{~m}_{2}}{\mathrm{~m}_{1}^{3}}-\frac{1}{\mathrm{~m}_{1}}\right) \frac{1}{\lambda^{2}},
$$

Note that if $|x|<1$, then the next equality is valid:

$$
\sum_{n=1}^{\infty} n^{2} x^{n-1}=\frac{2}{(1-x)^{3}}-\frac{1}{(1-x)^{2}} .
$$

By using this equality, we can rewrite (4.7), as follows:

$$
\tilde{\mathrm{R}}_{2}(\lambda)=\frac{2}{\lambda\left(1-\varphi_{\eta}(\lambda)\right)^{3}}-\frac{1}{\lambda\left(1-\varphi_{\eta}(\lambda)\right)^{2}}-\frac{2}{\lambda^{3} \mathrm{~m}_{1}^{2}}-\left(\frac{2 \mathrm{~m}_{2}}{\mathrm{~m}_{1}^{3}}-\frac{1}{\mathrm{~m}_{1}}\right) \frac{1}{\lambda^{2}} .
$$

Now, we will investigate asymptotic behavior of $\tilde{\mathrm{R}}_{2}(\lambda)$, as $\lambda \rightarrow 0$. For this aim, we can expand the Mac Lauren series of the function $\varphi_{\eta}(\lambda)=E\left(\exp \left(-\lambda \eta_{1}\right)\right)$, as $\lambda \rightarrow 0$. Note that, by the conditions of the Theorem 4.1, $\mathrm{E}\left(\eta_{1}^{3}\right)<\infty$. Moreover, the third-order asymptotic expansions of $\varphi_{\eta}(\lambda)$ can be written, as $\lambda \rightarrow 0$, as follows:

$$
\varphi_{\eta}(\lambda)=E\left(\mathrm{e}^{-\lambda \eta_{1}}\right)=1-\lambda E\left(\eta_{1}\right)+\frac{\lambda^{2}}{2 !} E\left(\eta_{1}^{2}\right)-\frac{\lambda^{3}}{3 !} E\left(\eta_{1}^{3}\right)+o\left(\lambda^{3}\right)
$$

Thus we get, as $\lambda \rightarrow 0$ :

$$
\left(1-\varphi_{\eta}(\lambda)\right)^{-2}=\frac{1}{\left(\lambda \mathrm{m}_{1}\right)^{2}}\left\{1+\lambda \mathrm{m}_{21}+\lambda^{2}\left[\frac{3}{4} \mathrm{~m}_{21}^{2}-\frac{1}{3} \mathrm{~m}_{31}\right]+\mathrm{o}\left(\lambda^{2}\right)\right\} .
$$

Here $\mathrm{m}_{\mathrm{k} 1} \equiv \mathrm{m}_{\mathrm{k}} / \mathrm{m}_{1}, \mathrm{k}=1,2,3$.

Substituting these expansions in the formula (4.8), we can obtain:

$$
\lambda \tilde{\mathrm{R}}_{2}(\lambda)=\frac{3}{2} \mathrm{~m}_{21}^{2}-\frac{1}{2} \mathrm{~m}_{21}-\frac{2}{3} \mathrm{~m}_{31}+\mathrm{o}(1) .
$$


Taking the limit as $\lambda \rightarrow 0$, we can get:

$$
\lim _{\lambda \rightarrow 0} \lambda \tilde{R}_{2}(\lambda)=\frac{1}{6}\left(9 m_{21}^{2}-3 m_{21}-4 m_{31}\right) .
$$

Applying the Tauberian theorem (see, [3], p.442) to (4.10), we can write:

$$
\lim _{x \rightarrow \infty} R_{2}(x)=\lim _{\lambda \rightarrow 0} \lambda \tilde{R}_{2}(\lambda)=\frac{1}{6}\left(9 m_{21}^{2}-3 m_{21}-4 m_{31}\right) \text {. }
$$

Namely, as $\mathrm{x} \rightarrow \infty$ :

$$
\mathrm{R}_{2}(\mathrm{x})=\frac{1}{6}\left(9 \mathrm{~m}_{21}^{2}-3 \mathrm{~m}_{21}-4 \mathrm{~m}_{31}\right)+\mathrm{o}(1) \text {. }
$$

Substituting the asymptotic expansions (4.11) in the formula (4.6), we obtain (4.2). Using the similar method, we can analogously obtain the asymptotic expansions for the third-order moments of the boundary functional $\mathrm{N}_{1}(\mathrm{x})$ in (4.3) and (4.4).

As a consequence of the formulas (4.1) and (4.2), we get the asymptotic expansion for the variance $\operatorname{Var}(\mathrm{N}(\mathrm{x}))$, which is well known in the literature.

This completes proof of the Theorem 4.1.

Taking into account the results of the Theorems 3.1 and 4.1, we can give the following important theorem.

Theorem 4.2. Let the conditions of the Theorem 3.1 be satisfied. Then the thirdorder asymptotic expansions for the first four moments of the boundary functional $\tau_{1}(\mathrm{x})$ can be given in the following form, as $\mathrm{x} \rightarrow \infty$ :

1) $\mathrm{E} \tau_{1}(\mathrm{x})=\frac{\alpha_{1}}{\mathrm{~m}_{1}} \mathrm{x}+\frac{\mathrm{m}_{2}}{2 \mathrm{~m}_{1}^{2}} \alpha_{1}+\mathrm{o}\left(\frac{1}{\mathrm{x}}\right)$,

2) $\mathrm{E} \tau_{1}^{2}(\mathrm{x})=\frac{\alpha_{1}^{2}}{\mathrm{~m}_{1}^{2}} \mathrm{x}^{2}+\left[\frac{\alpha_{2}-\alpha_{1}^{2}}{\mathrm{~m}_{1}}+\left(\frac{2 \mathrm{~m}_{2}}{\mathrm{~m}_{1}^{3}}-\frac{1}{\mathrm{~m}_{1}}\right) \alpha_{1}^{2}\right] \mathrm{x}+\left(\frac{3 \mathrm{~m}_{2}^{2}}{2 \mathrm{~m}_{1}^{4}}-\frac{2 \mathrm{~m}_{3}}{\mathrm{~m}_{1}^{3}}-\frac{\mathrm{m}_{2}}{2 \mathrm{~m}_{1}^{2}}\right) \alpha_{1}^{2}+\mathrm{o}(1)$,

3) $\mathrm{E} \tau_{1}^{3}(\mathrm{x})=\frac{\alpha_{1}^{3}}{\mathrm{~m}_{1}^{3}} \mathrm{x}^{3}+\left[\left(\frac{9 \mathrm{~m}_{2}}{2 \mathrm{~m}_{1}^{4}}-\frac{6}{\mathrm{~m}_{1}^{2}}\right) \alpha_{1}^{3}+\frac{3 \alpha_{1} \alpha_{2}}{\mathrm{~m}_{1}^{2}}\right] \mathrm{x}^{2}$

$$
+\left[\left(\frac{9 \mathrm{~m}_{2}^{2}}{\mathrm{~m}_{1}^{5}}-\frac{3 \mathrm{~m}_{3}}{\mathrm{~m}_{1}^{4}}+\frac{6}{\mathrm{~m}_{1}}\right) \alpha_{1}^{3}+\left(\frac{6 \mathrm{~m}_{2}}{\mathrm{~m}_{1}^{3}}-\frac{6}{\mathrm{~m}_{1}}\right) \alpha_{1} \alpha_{2}+\frac{\alpha_{3}}{\mathrm{~m}_{1}}\right] \mathrm{x}+\mathrm{o}(\mathrm{x}),
$$

4) $\mathrm{E} \tau_{1}^{4}(\mathrm{x})=\frac{\alpha_{1}^{4}}{\mathrm{~m}_{1}^{4}} \mathrm{x}^{4}+\left[\left(\frac{8 \mathrm{~m}_{2}}{\mathrm{~m}_{1}^{5}}-\frac{12}{\mathrm{~m}_{1}^{3}}\right) \alpha_{1}^{3}+\frac{6 \alpha_{1}^{2} \alpha_{2}}{\mathrm{~m}_{1}^{3}}\right] \mathrm{x}^{3}+\left[\left(\frac{30 \mathrm{~m}_{2}^{2}}{\mathrm{~m}_{1}^{6}}-\frac{8 \mathrm{~m}_{3}}{\mathrm{~m}_{1}^{5}}-\frac{54 \mathrm{~m}_{2}}{\mathrm{~m}_{1}^{4}}+\frac{36}{\mathrm{~m}_{1}^{2}}\right) \alpha_{1}^{3}\right.$

$$
\left.+\left(\frac{27 \mathrm{~m}_{2}}{\mathrm{~m}_{1}^{4}}-\frac{36}{\mathrm{~m}_{1}^{2}}\right) \alpha_{1}^{2} \alpha_{2}+\frac{3 \alpha_{2}^{2}+4 \alpha_{3} \alpha_{1}}{\mathrm{~m}_{1}^{2}}\right] \mathrm{x}^{2}+\mathrm{o}\left(\mathrm{x}^{2}\right),
$$

5) $\operatorname{Var}(\tau(\mathrm{x}))=\left[\left(\frac{\mathrm{m}_{2}}{\mathrm{~m}_{1}^{3}}-\frac{1}{\mathrm{~m}_{1}}\right) \alpha_{1}^{2}+\frac{\alpha_{2}-\alpha_{1}^{2}}{\mathrm{~m}_{1}}\right] \mathrm{x}+\left(\frac{11 \mathrm{~m}_{2}^{2}}{4 \mathrm{~m}_{1}^{4}}-\frac{2 \mathrm{~m}_{3}}{3 \mathrm{~m}_{1}^{3}}-\frac{\mathrm{m}_{2}}{2 \mathrm{~m}_{1}^{2}}\right) \alpha_{1}^{2}+\mathrm{o}(1)$,

where $\alpha_{\mathrm{n}}=\mathrm{E}\left(\xi_{1}^{\mathrm{n}}\right), \mathrm{m}_{\mathrm{n}}=\mathrm{E}\left(\eta_{1}^{\mathrm{n}}\right), \mathrm{n}=1,2,3$. 


\section{SIMULATION RESULTS}

Thus, main aim of this study has been attained. But it is advisable to test an adequateness of approximate formulas to the exact ones. For this purpose, using the Monte Carlo experiments we can give the following simulation results. First, let's denote by $\hat{E}\left(N_{1}^{k}\right)$ and $\tilde{E}\left(N_{1}^{k}\right),(k=1,2,3,4)$ the values of the $k^{\text {th }}$ moment $\left(E\left(N_{1}^{k}\right)\right)$ of the boundary functional $\left(\mathrm{N}_{1}(\mathrm{x})\right)$ calculated by using Monte Carlo simulation method and by using first three terms of the asymptotic expansions given by Theorem 4.1, respectively.

Moreover, we put

$$
\Delta_{\mathrm{k}}=\left|\hat{\mathrm{E}}\left(\mathrm{N}_{1}^{\mathrm{k}}\right)-\tilde{\mathrm{E}}\left(\mathrm{N}_{1}^{\mathrm{k}}\right)\right| ; \delta_{\mathrm{k}}=\frac{\Delta_{\mathrm{k}}}{\hat{\mathrm{E}}\left(\mathrm{N}_{1}^{\mathrm{k}}\right)} \cdot 100 \% ; A \mathrm{p}_{\mathrm{k}}=100 \%-\delta_{\mathrm{k}}, \mathrm{k}=1,2,3,4
$$

In other words, $\Delta_{\mathrm{k}}, \delta_{\mathrm{k}}, \mathrm{Ap}_{\mathrm{k}},(\mathrm{k}=1,2,3,4)$ are the absolute error, relative error and accuracy percent between the simulating and asymptotic values of $\mathrm{k}^{\text {th }}$ moment of the boundary functional of the process $\mathrm{X}(\mathrm{t})$, respectively. In this case, we assumed that the random variable $\eta_{1}$ has Erlang distribution with parameters $(2,20)$. For calculation of each quantity of $\hat{\mathrm{E}}\left(\mathrm{N}^{\mathrm{k}}\right),(\mathrm{k}=1,2,3,4), 10^{8}$ trajectories of the process $\mathrm{X}(\mathrm{t})$ were simulated.

Table 1: Comparison of the simulation and asymptotic values of $\mathrm{E}\left(\mathrm{N}_{1}(\mathrm{x})\right)$

\begin{tabular}{|c|c|c|c|c|c|}
\hline $\mathrm{x}$ & $\hat{\mathrm{EN}}_{1}(\mathrm{x})$ & $\mathrm{E} \mathrm{N}_{1}(\mathrm{x})$ & $\Delta_{1}$ & $\delta_{1}$ & $(\%) \mathrm{Ap}_{1}$ \\
\hline 2 & 21,0232 & 20,75 & 0,2732 & 1,2989 & 98,7011 \\
\hline 3 & 31,1014 & 30,75 & 0,3514 & 1,1298 & 98,7020 \\
\hline 4 & 40,7489 & 40,75 & 0,0011 & 0,0026 & 99,9974 \\
\hline 5 & 50,7625 & 50,75 & 0,0125 & 0,0246 & 99,2700 \\
\hline 6 & 60,716 & 60,75 & 0,034 & 0,0559 & 99,9944 \\
\hline 7 & 70,7345 & 70,75 & 0,0155 & 0,0219 & 99,9781 \\
\hline 8 & 80,7822 & 80,75 & 0,0322 & 0,0398 & 99,9602 \\
\hline 9 & 90,7365 & 90,75 & 0,0135 & 0,0148 & 99,9852 \\
\hline 10 & 100,7138 & 100,75 & 0,0362 & 0,0359 & 99,9641 \\
\hline
\end{tabular}

Table 2: Comparison of the simulation and asymptotic values of $\mathrm{E}\left(\mathrm{N}_{1}^{2}(\mathrm{x})\right)$

\begin{tabular}{|c|c|c|c|c|c|}
\hline $\mathrm{x}$ & $\hat{\mathrm{EN}}_{1}^{2}(\mathrm{x})$ & $\mathrm{EN}_{1}^{2}(\mathrm{x})$ & $\Delta_{2}$ & $\delta_{2}$ & $(\%) \mathrm{Ap}_{2}$ \\
\hline 2 & 441,9579 & 436,625 & 5,3329 & 1,2066 & 98,7933 \\
\hline 3 & 967,7679 & 956,625 & 11,1429 & 1,1514 & 98,8485 \\
\hline 4 & 1680 & 1676,625 & 3,975 & 0,2365 & 99,7634 \\
\hline 5 & 2600 & 2596,625 & 5,375 & 0,2065 & 99,7934 \\
\hline 6 & 3720 & 3716,625 & 0,025 & 0,0006 & 99,9993 \\
\hline 7 & 5040 & 5036,625 & 1,875 & 0,0372 & 99,9627 \\
\hline 8 & 6570 & 6556,625 & 9,375 & 0,1427 & 99,857 \\
\hline 9 & 8280 & 8276,625 & 1,175 & 0,0141 & 99,985 \\
\hline 10 & 10190 & 10196,625 & 6,625 & 0,0650 & 99,9349 \\
\hline
\end{tabular}

Table 3: Comparison of the simulation and asymptotic values of $\left.\mathrm{E}_{\mathrm{1}}(\mathrm{x})\right)$

\begin{tabular}{|c|c|c|c|c|c|}
\hline $\mathrm{x}$ & $\hat{\mathrm{EN}}_{1}^{3}(\mathrm{x})$ & $\mathrm{E}_{\mathrm{C}} \mathrm{N}_{1}^{3}(\mathrm{x})$ & $\Delta_{3}$ & $\delta_{3}$ & $(\%) \mathrm{Ap}_{3}$ \\
\hline 2 & 9460 & 9565 & 104,3 & 1,1024 & 98,8975 \\
\hline 3 & 30800 & 30472,5 & 320,5 & 1,0408 & 98,9591 \\
\hline 4 & 70100 & 70130 & 5 & 0,0071 & 99,9928 \\
\hline 5 & 135000 & 134537,5 & 112,5 & 0,0835 & 99,9164 \\
\hline 6 & 229000 & 229695 & 355 & 0,1547 & 99,8452 \\
\hline
\end{tabular}




\begin{tabular}{|c|c|c|c|c|c|}
\hline 7 & 361000 & 361602,5 & 212,5 & 0,0588 & 99,9411 \\
\hline 8 & 537000 & 536260 & 670 & 0,1247 & 99,8752 \\
\hline 9 & 759000 & 759667,5 & 427,5 & 0,0563 & 99,9436 \\
\hline 10 & 1036300 & 1037825 & 1525 & 0,1471 & 99,8528 \\
\hline
\end{tabular}

Table 4: Comparison of the simulation and asymptotic values of $\mathrm{E}\left(\mathrm{N}_{1}^{4}(\mathrm{x})\right)$

\begin{tabular}{|c|c|c|c|c|c|}
\hline $\mathrm{x}$ & $\hat{\mathrm{EN}}_{1}^{4}(\mathrm{x})$ & $\mathrm{EN}_{1}^{4}(\mathrm{x})$ & $\Delta_{4}$ & $\delta_{4}$ & $(\%) \mathrm{Ap}_{4}$ \\
\hline 2 & 210000 & 212000 & 2190 & 1,0438 & 98,9561 \\
\hline 3 & 971000 & 981000 & 9900 & 1,0194 & 98,9805 \\
\hline 4 & 2560000 & 2560000 & 700 & 0,0273 & 99,9726 \\
\hline 5 & 7030000 & 7025000 & 8100 & 0,1151 & 99,8848 \\
\hline 6 & 14300000 & 14292000 & 28000 & 0,1962 & 99,8037 \\
\hline 7 & 26100000 & 26117000 & 19000 & 0,0728 & 99,9271 \\
\hline 8 & 44200000 & 44096000 & 75000 & 0,1697 & 99,8302 \\
\hline 9 & 70000000 & 70065000 & 57000 & 0,0814 & 99,9185 \\
\hline 10 & 105900000 & 106100000 & 200000 & 0,1888 & 99,8111 \\
\hline
\end{tabular}

Remark. As seen from the presented tables, the approximating formulas provide a high accuracy even for small values of the parameter $\mathrm{x}$. For example, the accuracy percentage (AP) in the tables is greater than $\% 99$, for each value of parameters $x \geq 4$. This indicates that the obtained asymptotic expansion can be safely applied on different problems of inventory or queuing models, even for not large values of parameter $\mathrm{x}$.

Acknowledgements: The authors express their thanks to Professor A.V. Skorohod, Michigan State University, for his supports and valuable advices.

\section{REFERENCES}

1. G. Alsmeyer, Some relations between harmonic renewal measures and certain first passage times, Statistics and Probability Letters, 12, 1, 19-27, 1991.

2. M. Brown and H. Solomon, A second-order approximation for variance of a renewal reward process, Stochastic Processes and Their Application, 3, 301-314, 1975.

3. W. Feller, An Introduction to Probability Theory and Its Applications II, 2nd Ed., New York, 680 p., 1971.

4. W. S. Jewell, Fluctuation of a Renewal Reward Process, Journal of Mathematical Analysis and Applications, 19, 309-329, 1967.

5. T. A. Khaniyev, H. Ozdemir, S. Maden, Calculating probability characteristics of a boundary functional of a semi-continuous random process with reflecting and delaying screens, Applied Stochastic Models and Data Analysis, 14, 117-123, 1998.

6. T. A. Khaniyev, Z. Mammadova, On the stationary characteristics of the extended model of type $(\mathrm{s}, \mathrm{S})$ with Gaussian distribution of summands, Journal of Statistical Computation and Simulation, 76, 10, 861-874, 2006.

7. T. A. Khaniyev, About moments of generalized renewal process, Transactions of NAS of Azerbaijan, Series of Phys. Tech. and Math. Sciences, 25, 1, 95-100, 2005.

8. T. A. Khaniyev, T. Kesemen, R. T. Aliyev, A. Kokangul, Asymptotic expansions for the moments of a semi-Markovian random walk with exponential distributed interference of chance, Statistics \& Probability Letters, 78, 6, 785-793, 2008.

9. T. A. Khaniyev, R. T. Aliyev, Z. Kucuk, N.O. Bekar, On the distributions of a renewal reward process and it's additive functional, Mathematical and Computational Applications, 13, 1, 41-50, 2008. 